Jurnal Sain Veteriner, Vol. 37. No. 1. Juni 2019, Hal. 69-79

DOI : $10.22146 /$ jsv.23358

ISSN 0126-0421 (Print), ISSN 2407-3733 (Online)

Tersedia online di https://jurnal.ugm.ac.id/jsv

\title{
Prevalensi Strain Avian Pathogenic Escherichia coli (APEC) Penyebab Kolibasilosis pada Burung Puyuh
}

\section{Prevalence of Avian Pathogenic Escherichia coli (APEC) Strains Causes Colibacillosis in Quail}

\author{
Wahyu Prihtiyantoro ${ }^{1 *}$, Khusnan ${ }^{1}$, Mitra Slipranata ${ }^{2}$ dan Imron Rosyidi ${ }^{2}$ \\ Akademi Peternakan Brahmaputra, Jl. Ki Ageng Pemanahan, Nitikan, Sorosutan, Umbulharjo Yogyakarta \\ ${ }^{2}$ Fakultas Kedokteran Hewan, Universitas Gadjah Mada, Jl. Fauna 2, Karangmalang, \\ Yogyakarta 55281 \\ *E-mail: wahyumatra@gmail.com
}

Naskah diterima : 23 Januari 2019, direvisi : 10 Mei 2019, disetujui : 24 Mei 2019

\begin{abstract}
Avian Pathogenic Escherichia coli (APEC) is a pathogen that causes colibacillosis in poultry, including salpingitis, omphalitis, cellulitis, swollen head syndrome, coligranuloma yolk sac inflammation, and air sacs inflammation. APEC is a zoonotic strain which spread through raw meat and processed meat products of animals and birds. In this research, the isolation and identification of Escherichia coli were done by using selective media MacConkey, Kligger Iron Agar, and Gram staining. Polymerase chain reaction (PCR) was used to analyse genetopically to detect 16SrRNA genes, vt1 genes, and vt2 genes. Thirty one $(55,36 \%)$ isolates of 56 specimens collected from quail were detected as Escherichia coli. The detection of APEC strains towards 31 Escherichia coli isolates were done by using polymerase chain reaction (PCR) with vt 1 and vt 2 specific primer. The results showed that $32,26 \%$ (10/31) was APEC strains and $67.74 \%$ was non-APEC strains. From 10 isolates, $90 \%$ had vt1 gene and $10 \%$ had vt2 gene. Escherichia coli isolates were found in eyes $(32,26 \%)$, infraorbital sinus fluid $(32,26 \%)$, nasal fluid $(16,20 \%)$, also in lungs, air sacs, ascites, and heart for 3,2\% each. The isolates could not be found in the specimens from the skull. As a zoonotic agent, the isolates have an impact on human health.
\end{abstract}

Keywords: APEC; colibacillosis; quail; vt1; vt2

\begin{abstract}
Abstrak
Avian Pathogenic Escherichia coli (APEC) merupakan patogen sebagai penyebab kolibasilosis pada unggas, diantaranya menyebabkan salpingitis, omfalitis, selulitis, sindrom kepala bengkak, koligranuloma radang yolk sac serta radang kantung udara. APEC merupakan strain zoonosis yang disebarkan melalui daging dan produk daging olahan dari hewan dan unggas. Pada penelitian ini dilakukan isolasi dan identifikasi Escherichia coli menggunakan media selektif MacConkey, Kligger Iron Agar dan pewarnaan Gram. Polymerase chain reaction (PCR) digunakan untuk penilaian genotipik untuk mendeteksi adanya gen 16SrRNA dan gen $v t 1$ serta $v t 2$. Dari 56 sampel spesimen burung puyuh, $31(55,36 \%)$ isolat terdeteksi sebagai Escherichia coli. Deteksi strain APEC terhadap 31 isolat Escherichia coli digunakan polymerase chain reaction (PCR) menggunakan gen $v t 1$ dan gen $v t 2$ primer spesifik menunjukkan 32,26\% (10/31) sebagai strain APEC dan 67,74\% non APEC. Distribusi gen vt1 dan vt2 dari 10 isolat terdiri dari $90 \%$ memiliki gen $v t 1$ dan 10\% memiliki gen $v t 2$. Isolat Escherichia coli yang berasal dari mata sebesar $32,26 \%(11 / 31)$, dari cairan sinus infraorbitalis 32,26\% (11/31), cairan hidung 16,2\% (5/31), paru, kantung hawa, cairan asites dan jantung masing-masing 3,2\% (1/31), serta tidak ditemukan pada spesimen yang berasal dari tulang tengkorak. Sebagai agen zoonosis, isolat memiliki dampak penting pada kesehatan manusia.
\end{abstract}

Kata Kunci: APEC; kolibasilosis; puyuh; vt1; vt2

\section{Pendahuluan}

Escherichia coli merupakan bakteri penyebab

kolibasilosis pada unggas (Roy et al., 2004; Akbar et al., 2009; Antao et al., 2008). Strain APEC (Avian

Pathogenic Escherichia coli (APEC) menyebabkan

kolibasilosis pada ayam, kalkun, dan unggas lainnya 
Wahyu Prihtiyantoro, et. al.

(Ramirez et al. 2009), seperti burung puyuh (Roy et al. 2006). Strain APEC menyebabkan penyakit primer maupun sekunder pada ayam dan bangsa unggas lain (Antao et al., 2008), yang bersifat sistemik dan menimbulkan bakteriemia (Suryani et al., 2014).

Kolibasilosis pada unggas menyebabkan kerugian ekonomi karena menurunnya produksi, menyebabkan kematian dan bertambahnya biaya pengobatan (Barnes et al., 1997; Bilge et al., 1989; Nakazato et al., 2009; D1'az-Sa'nchez et al., 2012; Sarah et al., 2015). Pada unggas kolibasilosis ditandai dengan perikarditis, air sacculitis dan perihepatitis (Calnek et al., 1997), salpingitis, omfalitis, selulitis, sindroma kepala bengkak, koligranuloma radang yolk sac serta air sacculitis (McPeake et al., 2005; Hamad et al., 2012). Menurut Barnes et al. (2003) kolibasilosis pada unggas menyebabkan meningitis, panophthalmitis (mata bengkak), osteoartritis, sinositis dan koligranuloma yang ditandai dengan beberapa granuloma di hati, sekum, duodenum dan mesenterium.

Pada burung puyuh kolibasilosis sering berhubungan pada sistem pencernaan, pernafasan serta infeksi pada organ dan jaringan lainnya (Kabir, 2010). Kolibasilosis menyebabkan perubahan pada paru, hati, limpa, usus, ginjal dan jantung (Akbar et al., 2009). Kolibasilosis pada burung puyuh menurut Ito et al. (1990) menyebabkan hepatitis dan perikarditis. Koliseptisemia pada unggas ditemukan perikarditis, hepatitis, folikulitis, pembesaran limpa dan peritonitis (Oh et al., 2011). Menurut Saif et al. (2008) burung puyuh yang dibudidayakan rentan terhadap kolibasilosis. Pada penelitian ini dilakukan isolasi Escherichia coli yang berasal dari berbagai spesimen dari burung puyuh petelur dan deteksi strain APEC secara genotip.

\section{Materi dan Metode}

Penelitian ini menggunakan 56 spesimen yang berasal dari kasus kolibasilosis pada burung puyuh petelur (Tabel 1). Identifikasi Escherichia coli didasarkan pada karakter koloni pada media MacConkey, Kligger Iron Agar dan karakterisasi morfologi menggunakan pewarnaan Gram. Spesimenspesimen ditanam pada media THB 24 jam jam pada $37^{\circ} \mathrm{C}$. Bakteri ditanamkan dari THB pada media MacConkey (Oxoid) dan diinkubasi selama 24 jam pada $37^{\circ} \mathrm{C}$ seperti yang dilakukan Zinnah et al. (2007); Mohamed et al. (2014) dan Abd El Tawab (2015). Koloni yang diduga Escherichia coli dari media MacConkey ditanam pada media KIA (Kligger Iron Agar) seperti yang dilakukan Carson et al. (2001) dan Afroz et al. (2013). Pewarnaan Gram dikerjakan seperti yang dilakukan Lowy (2009).

Seluruh isolat dilakukan ekstraksi deoxyribonucleic acid (DNA) yang dilanjutkan dengan PCR untuk amplifikasi gen 16SrRNA, amplifikasi gen $v t 1$ dan $v t 2$. Ekstraksi DNA digunakan kit ektraksi DNA (Dneasy Qiagen) dengan prosedur sesuai dengan rekomendasi pabrik. Primer selektif untuk mengamplifikasi gen 16SrRNA E. coli digunakan primer yang didesain berdasarkan Knobl et al. (2004).

Amplifikasi gen 16SrRNA spesifik E. coli menggunakan primer ECP79F dan ECR620R dilakukan dengan mencampur larutan PCR mix (Supermix, Invitrogen, Germany) dengan 2,5 $\mu 1$ (0,6 $\mu \mathrm{M})$ masing-masing primer dan $2 \mu 1$ DNA ke dalam tabung PCR hingga mencapai volume total $25 \mu 1$, selanjutnya tabung yang telah berisi larutan dimasukkan ke dalam alat thermal cycle (Mastercycler, Eppendorf, Germany).

Urutan basa nukleotida dari primer dan program PCR disajikan pada Tabel 1. Campuran reaksi terdiri atas 2,5 $\mu 1$ masing-masing primer I dan primer II, $1 \mu \mathrm{g}$ DNA dan PCR mix sampai volume 25 $\mu 1$. Program PCR untuk amplifikasi gen 16SrRNA E. coli setelah denaturasi awal lima menit pada 
temperatur $94^{\circ} \mathrm{C}$, fragmen gen target diamplifikasi dalam 40x siklus. Masing-masing siklus dengan program denaturasi selama 45 detik pada suhu $94^{\circ} \mathrm{C}$, annealing 45 detik pada suhu $50^{\circ} \mathrm{C}$ dan ekstensi selama 1,5 menit pada suhu $72^{\circ} \mathrm{C}$ (Knobl et al., 2004).

Produk PCR dianalisis dengan menggunakan elektroforesis dalam 2\% gel agarosa (Sigma), dan bufer (TAE) (0,04 M Tris; 0,001 M EDTA; pH 7,8). Sebanyak $10 \mu 1$ produk PCR dicampur dengan $\pm 3 \mu 1$ loading buffer, pada tegangan $100 \mathrm{~V}$ selama 30 menit. Setelah elektroforesis pita-pita DNA pada agar diwarnai dengan larutan Sybr save staining dan divisualisasikan mengunakan UV transilluminator.

Kolibasilosis pada unggas menyebabkan kerugian ekonomi karena menurunnya produksi, menyebabkan kematian dan bertambahnya beaya pengobatan (Barnes et al., 1997; Bilge et al., 1989; Nakazato et al., 2009; D1'az-Sa'nchez et al., 2012; Sarah et al., 2015). Pada unggas kolibasilosis ditandai dengan perikarditis, air sacculitis dan perihepatitis (Calnek et al., 1997), salpingitis, omfalitis, selulitis, sindroma kepala bengkak, koligranuloma radang yolk sac serta air sacculitis (McPeake et al., 2005; Hamad et al., 2012). Menurut Barnes et al. (2003) kolibasilosis pada unggas menyebabkan meningitis, panophthalmitis (mata bengkak), osteoartritis, sinositis dan koligranuloma yang ditandai dengan beberapa granuloma di hati, sekum, duodenum dan mesenterium.

Pada burung puyuh kolibasilosis sering berhubungan pada sistem pencernaan, pernafasan serta infeksi pada organ dan jaringan lainnya (Kabir, 2010). Kolibasilosis menyebabkan perubahan pada paru, hati, limpa, usus, ginjal dan jantung (Akbar et al., 2009). Kolibasilosis pada burung puyuh menurut Ito et al. (1990) menyebabkan hepatitis dan perikarditis. Koliseptisemia pada unggas ditemukan perikarditis, hepatitis, folikulitis, pembesaran limpa dan peritonitis
(Oh et al., 2011). Menurut Saif et al. (2008) burung puyuh yang dibudidayakan rentan terhadap kolibasilosis. Pada penelitian ini dilakukan isolasi Escherichia coli yang berasal dari berbagai spesimen dari burung puyuh petelur dan deteksi strain APEC secara genotip.

\section{Materi dan Metode}

Penelitian ini menggunakan 56 spesimen yang berasal dari kasus kolibasilosis pada burung puyuh petelur (Tabel 1). Identifikasi Escherichia coli didasarkan pada karakter koloni pada media MacConkey, Kligger Iron Agar dan karakterisasi morfologi menggunakan pewarnaan Gram. Spesimenspesimen ditanam pada media THB 24 jam jam pada $37^{\circ} \mathrm{C}$. Bakteri ditanamkan dari THB pada media MacConkey (Oxoid) dan diinkubasi selama 24 jam pada $37^{\circ} \mathrm{C}$ seperti yang dilakukan Zinnah et al. (2007); Mohamed et al. (2014) dan Abd El Tawab (2015). Koloni yang diduga Escherichia coli dari media MacConkey ditanam pada media KIA (Kligger Iron Agar) seperti yang dilakukan Carson et al. (2001) dan Afroz et al. (2013). Pewarnaan Gram dikerjakan seperti yang dilakukan Lowy (2009).

Seluruh isolat dilakukan ekstraksi deoxyribonucleic acid (DNA) yang dilanjutkan dengan PCR untuk amplifikasi gen 16SrRNA, amplifikasi gen $v t 1$ dan $v t 2$. Ekstraksi DNA digunakan kit ektraksi DNA (Dneasy Qiagen) dengan prosedur sesuai dengan rekomendasi pabrik. Primer selektif untuk mengamplifikasi gen 16SrRNA E. coli digunakan primer yang didesain berdasarkan Knobl et al. (2004).

Amplifikasi gen 16SrRNA spesifik E. coli menggunakan primer ECP79F dan ECR620R dilakukan dengan mencampur larutan PCR mix (Supermix, Invitrogen, Germany) dengan 2,5 $\mu 1$ (0,6 $\mu \mathrm{M})$ masing-masing primer dan $2 \mu 1$ DNA ke dalam 
Wahyu Prihtiyantoro, et. al.

tabung PCR hingga mencapai volume total $25 \mu \mathrm{l}$, selanjutnya tabung yang telah berisi larutan dimasukkan ke dalam alat thermal cycle (Mastercycler, Eppendorf, Germany).

Urutan basa nukleotida dari primer dan program PCR disajikan pada Tabel 1. Campuran reaksi terdiri atas 2,5 $\mu 1$ masing-masing primer I dan primer II, $1 \mu \mathrm{g}$ DNA dan PCR mix sampai volume 25 $\mu 1$. Program PCR untuk amplifikasi gen 16SrRNA E. coli setelah denaturasi awal lima menit pada temperatur $94^{\circ} \mathrm{C}$, fragmen gen target diamplifikasi dalam 40x siklus. Masing-masing siklus dengan program denaturasi selama 45 detik pada suhu $94^{\circ} \mathrm{C}$, annealing 45 detik pada suhu $50^{\circ} \mathrm{C}$ dan ekstensi selama 1,5 menit pada suhu $72^{\circ} \mathrm{C}$ (Knobl et al., 2004).

Produk PCR dianalisis dengan menggunakan elektroforesis dalam 2\% gel agarosa (Sigma), dan bufer (TAE) (0,04 M Tris; 0,001 M EDTA; pH 7,8). Sebanyak $10 \mu 1$ produk PCR dicampur dengan $\pm 3 \mu 1$ loading buffer, pada tegangan $100 \mathrm{~V}$ selama 30 menit. Setelah elektroforesis pita-pita DNA pada agar diwarnai dengan larutan Sybr save staining dan divisualisasikan mengunakan UV transilluminator.

Tabel 1. Polymerase chain reaction (PCR) primer untuk amplifikasi gen $16 \mathrm{SrRNA}, v t 1$ dan $v t 2$

\begin{tabular}{lllll}
\hline No & Gen & Primer Sekuen (5'-3') & $\begin{array}{l}\text { Ukiran (bp) } \\
\text { Produk PCR }\end{array}$ \\
\hline & & & & 544bp \\
& 16S & 5'-GAAGCTTGCTTCTTTGCT-3' & Knobl, et al. (2004). \\
2 & $v t 1$ & 5'-GAGCCCGGGGATTTCACAT-3' & 5'-CAGTTAATGTGGTGGCGAAG-3' & 130bp \\
& & 5'-CTGCTAATAGTTCTGCGCATC-3' & Bottero et al. (2004) \\
3 & \multirow{2}{*}{$v t 2$} & 5'-CTTCGGTATCCTATTCCCGG-3' & 346bp \\
& & 5'GGATGCATCTCTGGTCATTG-3' & Bottero et al. (2004) \\
\hline
\end{tabular}

\section{Hasil dan Pembahasan}

Pada penelitian ini dari 56 spesimen yang berasal dari jaringan dan organ burung puyuh sakit (Tabel 2) diperoleh 55,36\% (31/56) isolat terdeteksi sebagai Escherichia coli dan 32,26\% (10/31) isolat terdeteksi sebagai strain APEC. Identifikasi Escherichia coli berdasarkan karakter pada media MacConkey, Kligger Iron Agar (KIA) dan pewarnaan Gram, seperti terlihat pada Gambar 1 dan Gambar 2.

Karakter Escherichia coli pada media MacConkey akan tumbuh koloni berwarna merah muda dan terang (Zinnah et al., 2007; Mohamed et al., 2014 dan Abd El Tawab et al., 2015), pada media KIA Escherichia coli akan tumbuh dan mengubah warna media miring dan tegak dari merah menjadi kuning, tidak membetuk $\mathrm{H}_{2} \mathrm{~S}$ dan terbentuk gas (Anonimus, 2016; Carson et al., 2001; Afroz et al., 2013). Pada pewarnaan Gram morfologi Escherichia coli berwarna merah muda, berbentuk batang kecil serta masuk dalam golongan Gram-negatif.

Pada penelitian ini prevalensi kolibasilosis pada burung puyuh petelur sebesar 55,36\% (31/56) dan prevalensi APEC sebesar 32,26\%. Prevalensi ini mirip dengan hasil penelitian Roy et al. (2006), kolibasilosis pada burung puyuh sebesar 54,5\%. Hamad et al., (2012) melaporkan prevalensi kolibasilosis pada burung puyuh sebesar $18,2 \%$.

Prevalensi kolibasilosis pada burung puyuh lebih kecil dibandingkan dengan kolibasilosis pada broiler. Beberapa hasil penelitian menunjukkan kolibasiosis pada broiler sebesar 85\% (Sepehrie dan Zadeh, 2006), 81,67\% Rehman et al. (2014), 81,67\% (Mamun et al., 2016), 70,16\% (Elsayed et al. 2015), 58\% (Mitra et al., 2004), 78,86\% (Jakaria et al., 2012). Beberapa peneliti melaporkan prevalensi kolibasilosis pada broiler lebih rendah dibandingkan hasil penelitian ini, yaitu sebesar 52\% (Roy et al., 2012) dan 18,2\% (Hammad et al., 2012). 
Tabel 2. Jenis spesimen dan hasil identifikasi Escherichia coli dan deteksi gen $v t 1$ dan $v t 2$

\begin{tabular}{|c|c|c|c|c|c|}
\hline \multirow[t]{3}{*}{ No. } & \multicolumn{2}{|l|}{ Spesimen } & \multicolumn{3}{|l|}{ Jumlah Isolat } \\
\hline & \multirow[t]{2}{*}{ Asal } & \multirow[t]{2}{*}{ Jumlah } & \multirow{2}{*}{$\begin{array}{c}\text { Escherichia } \\
\text { coli }\end{array}$} & \multicolumn{2}{|c|}{ Strain APEC } \\
\hline & & & & $v t 1$ & $v t 2$ \\
\hline 1 & Mata kanan & 12 & 8 & 2 & - \\
\hline 2 & Mata kiri & 8 & 3 & - & - \\
\hline 3 & Cairan Sinus & 17 & 11 & 2 & - \\
\hline 4 & Cairan Hidung & 6 & 5 & 3 & 1 \\
\hline 6 & Paru & 4 & 1 & - & - \\
\hline 7 & Kantung hawa & 3 & 1 & 1 & - \\
\hline 8 & Cairan asites & 3 & 1 & - & - \\
\hline 9 & Jantung & 1 & 1 & 1 & - \\
\hline 10 & Subkepala & 2 & - & - & - \\
\hline & Jumlah & 56 & 31 & 9 & 1 \\
\hline & Persentase & & $55,36 \%$ & & \\
\hline
\end{tabular}

Kolibasilosis merupakan sindroma kompleks pada unggas yang mencakup berbagai macam penyakit seperti septikemia, selulitis, airs acculitis, perikarditis, dan sindroma kepala bengkak (Rodriguez-Siek et al., 2005). Manifestasi klinis termasuk enteritis, artritis, omfalitis, koligranuloma, salpingitis, septikemia, airsacculitis, penyakit pernapasan kronis, sindrom kepala bengkak, peritonitis, osteomyelitis, sinovitis, selulitis, dan lain-lain (Mater et al., 2011; Barbieri et al., 2013). Pada penelitian ini 31 isolat Escherichia coli berasal dari mata sebesar 35,5\% (11/31), cairan sinus infraorbitalis $35,5 \%(11 / 31)$, cairan hidung $16,2 \%$ (5/31), paru-paru, kantung hawa, cairan asites dan jantung masing-masing 3,2\% (1/31), serta tidak ditemukan pada spesimen asal tulang tengkorak.

Strain APEC dilaporkan telah diisolasi dari koliseptisemia dan kasus selulitis pada burung puyuh Jepang (Coturnix coturnix japonica) (Arenas et al., 1999; Roy et al., 2006). APEC merupakan strain patogen sebagai menyebab kolibasilosis pada bangsa unggas (Kalin et al, 2012; Hussein et al, 2013). APEC sering menyebabkan kolibasilosis yang berhubungan dengan ekstraintestinal pada ayam, kalkun, dan burung lainnya (Ramirez et al., 2009; Salehi et al., 2007; Soon-Gu et al., 2008), serta pada burung puyuh (Arenas et al., 1999; Salehi dan Ghanbarpour, 2010).

Hasil penelitian dengan menggunakan metode polymerase chain reaction (PCR) terdentifikasi $32,26 \%$ (10/31) sebagai strain APEC dan sisanya tidak terdeteksi sebagai strain APEC (Gambar 3), Pada strain APEC tersebut distribusi gen $v t 1$ sebesar 90\% (9/10) dan gen $v t 2$ sebesar $10 \%(1 / 10)$. Isolat-isolat tersebut berasal dari spesimen usapan mata $20 \%(2 / 10)$, sinus infraorbitalis $20 \%(2 / 10)$, cairan hidung $30 \%(4 / 10)$, kantung hawa $10 \%(1 / 10)$ dan jantung 10\% (1/10)

Strain APEC merupakan strain Escherichia coli yang memproduksi verotoxins ( $v t$ ) atau shigatoxins (stx) (Manoj et al., 2011; Nataro dan Kaper, 1998; Ludwig et al., 2002). Verotoxins ( $v t$ ) atau shigatoxins (stx) merupakan sitotoksin yang diproduksi oleh beberapa Escherichia coli enteropathogenic, dan telah ditemukan pada Escherichia coli isolat asal burung (Salehi et al., 2007). Beberapa srain APEC hanya memiliki gen $v t 1$ (stx1) atau vt2 (air sacculitis) saja, atau keduanya (Nataro dan Kaper, 1998). Strain yang hanya memiliki 
Wahyu Prihtiyantoro, et. al.

$v t 2$ (stx2) lebih patogen dibandingkan dengan strain yang memiliki vt 1 (stx1) atau bahkan strain membawa kedua $v t 1$ (stx1) dan $v t 2$ (stx2) (Nataro dan Kaper, 1998; Ludwig et al., 2002). Pada penelitian ini ditemukan satu isolat memiliki gen $v t 2$ yang berasal dari cairan hidung.

Prevalensi strain APEC pada hasil penelitian ini lebih besar dibandingkan dengan laporan Hemmatinezhad et al. (2015), bahwa prevalensi strain APEC isolat burung puyuh sebesar 27,77\%. Prevalensi APEC asal bangsa unggas dilaporkan bervariasi. Prevalensi strain APEC pada ayam petelur yang dilaporkan Soon-Gu et al. (2008) dan Hasan et al., 2010) sebesar $31,3 \%$ dan $31,82 \%$. Prevalensi APEC pada broiler dilaporkan Hasan et al. (2010) dan Radwan et al. (2014) sebesar 34\% dan 41,5\%. Prevalensi APEC isolat asal kalkun sebesar 11\% (Emery et al., 1992), burung unta sebesar 9,33\%, dan pada kalkun 23,53\% (Hemmatinezhad et al., 2015).

Distribusi gen $v t 1$ isolat asal burung puyuh yang diteliti lebih banyak dibandingkan dengan isolat yang memiliki gen $v t 2$ yaitu $90 \%$ memiliki gen $v t 1$ dan $10 \%$ memiliki gen $v t 2$. Moon et al. (2006) melaporkan prevalensi gen virulensi pada Escherichia coli isolat burung sebesar stx $1(1,2 \%)$ dan stx 2 (6\%). Salehi dan Ghanbarpour (2010) melaporkan isolat asal burung puyuh tidak memiliki gen $s t x 1$ dan stx 2 .

Distribusi gen stx 1 dan stx 2 strain APEC isolat asal broiler dilaporkan oleh Mamun et al. (2016) sebesar 10,20\% (5/49) dan 53,06\% (26/49) serta $12,24 \%(6 / 49)$ isolat ditemukan positif untuk kedua stx 1 dan gen stx 2 , dan sisanya $22,46 \%$ (12/49) negatif. El-Hewairy et al. (2009) melaporkan distribusi Escherichia coli isolat sapi yang memiliki gen $v t 1$ dan $v t 2$ sebesar $54,02 \%$ dan $26,43 \%$, isolat asal domba sebesar $21,42 \%$ dan $25 \%$, isolat asal unta sebesar 1,7\% dan 36,7\% (El-Hewairy et al., 2009). Jamshidi et al. (2016) melaporkan isolat asal broiler tidak memiliki gen stxl dan stx2.

Isolat yang memproduksi verotoksin 1 dan verotoksin 2 dapat menyebabkan penyakit pada unggas dan manusia (Manoj et al., 2011). APEC merupakan strain Escherichia coli yang bersifat zoonosis, pada manusia menyebabkan wabah kolitis hemoragi dan hemolytic uremic syndrome (HUS) (Law, 2000; Naylor et al., 2005; Aidar-Ugrinovich et al., 2007; Lee et al., 2011) maupun meningitis neonatal (Alonso et al., 2016). Ternak merupakan reservoir utama APEC (Dho-Moulin dan Fairbrother 1999). Menurut Radwan et al. (2014) unggas berperan sebagai reservoir APEC, dapat disebarkan melalui telor dan daging ayam maupun kalkun maupun unggas lain.

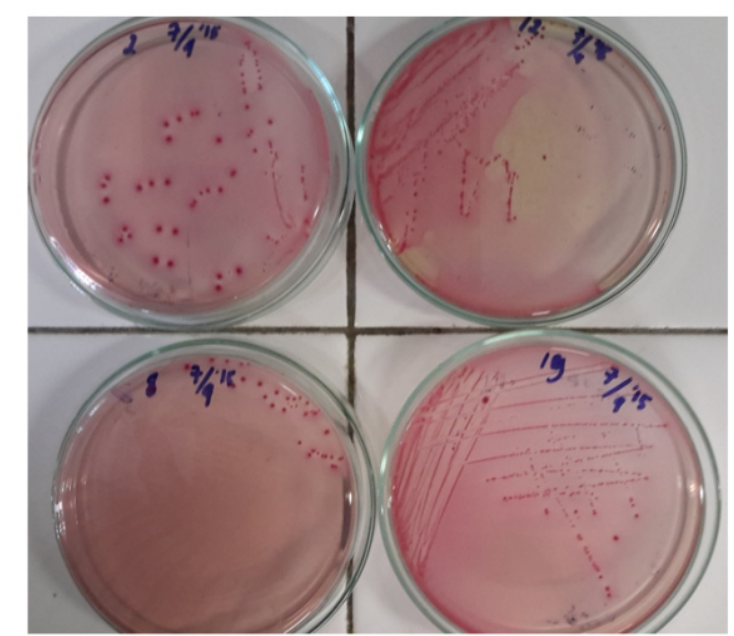

Gambar 1. Koloni bakteri yang diduga E. coli pada media MacConkey 


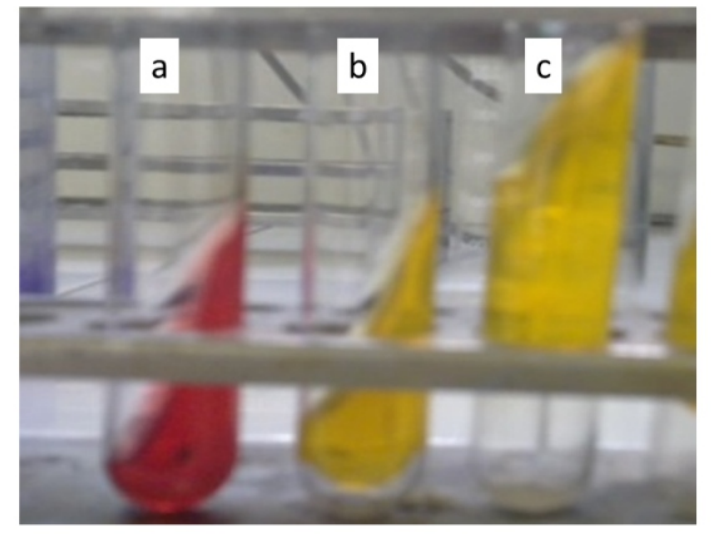

Gambar 2. Kligger Iron Agar (KIA) (a). E. coli pada KIA merubah warna dari merah menjadi kuning dan terbentuk gas (b dan c).

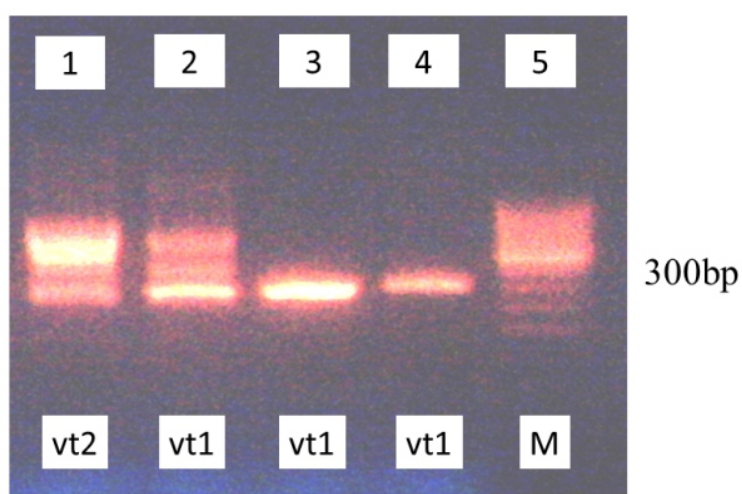

Gambar 3. Gel elektroforesis hasil PCR gen vt1 dan vt2 pada E. coli. Lajur 5 (Marker), Lajur 1, 3, 4 dan 5 (vt1: 130bp). Lajur 2 (vt2: 346bp)

\section{Kesimpulan}

Strain APEC ditemukan pada kasus kolibasilosis burung puyuh petelur sebesar $32,26 \%$, yang berasal dari mata, cairan sinus infraorbitalis, cairan hidung, paru, kantung hawa, cairan asites dan jantung. Ditemukan 90\% mempunyai gen vt1 dari mata, cairan sinus, paru, kantung hawa, cairan asites dan jantung, serta $10 \% v t 2$ dari cairan hidung. Sebagai agen yang bersifat zonosis, isolat-isolat ini dapat berdampak pada kesehatan manusia.

\section{Ucapan Terima Kasih}

Penelitian ini merupakan bagian dari
Penelitian Fundamental yang dibiayai oleh DRPM Kemenristekdikti melalui Dana DIPA Kopertis Wilayah V Tahun Anggaran 2015-2016. Peneliti mengucapkan terima kasih atas pendanaannya dan terima kasih kepada pihak-pihak yang telah membantu dalam penelitian ini.

\section{Daftar Pustaka}

Afroz H., Sultana F., Fakruddin M., Khan Z.U.M. and Datta S. (2013) Isolation of Escherichia coli and Staphylococcus aureus from Full Cream Powder Milk Sold Under Market Conditions at Dhaka, Bangladesh and Their Antibiotic Susceptibility. J. Adv. Sci. Res. 
Wahyu Prihtiyantoro, et. al.

$4(3): 27-31$.

Aidar-Ugrinovich L., Blanco J., Blanco M., Blanco J.E., Leomil L., Dahbi G., Mora A., Onuma D.L., Silveira W.D. and de Castro P.A.F. (2007). Serotypes, virulence genes, and intimin types of Shiga toxin-producing Escherichia coli (STEC) and enteropathogenic E. coli (EPEC) isolated from calves in Sao Paulo, Brazil. Int. J. Food. Microbiol. 115:297-306.

Akbar H., Khan M., Khan A.A., Khan M.A., Shuaib M., Akbar S.F., Manzoor S., Irshadurrehman S., Ahmad L., Ali R., Khalid R. and Idrees M. (2009) Comparative efficacy of doxycycline and flumequine against experimentally induced colibacillosis in broiler chicks. J. of Vet. Med. and Anim. Health. 1 (2):17-22.

Alonso M.Z., Krüger A., Sanz M.E., Padola N.L. and Lucchesi P.M.A. (2016) Serotypes, virulence profiles and stx subtypes of Shigatoxigenic Escherichia coli isolated from chicken derived products. Rev. Argent. Microbiol. 48(4):325-328.

Anonimus (2016) Instructions for use Kligger Iron $\begin{array}{lllll}\text { A } & \mathrm{g} & \mathrm{a} & \mathrm{r}\end{array}$ https://catalog.hardydiagnostics.com/cp_p rod/Content/hugo/KliglerIronAgarKIA.ht $\mathrm{m}$

Antao EM., Glodde S., Li G., Sharifi R., Homeier T. and Laturnus C. (2008). Thechicken as anatural model for extra intestinal infections caused by avian pathogenic Escherichia coli (APEC). Microbiol. Pathol. 45:361-369.

Arenas A, Vicente S. and Luque I. (1999). Outbreak of septicaemic colibacillosis in Japanese quail (Coturnix coturnix japonica). Zentralbl Veterinarmed B. 46:399-404.

Barbieri N.L., de Oliveira A.L., Tejkowski T.M., Pavanelo D.B., Rocha D.A., Matter L.B., Callegari-Jacques S.M., de Brito B.G., Horn F. (2013) Genotypes and pathogenicity of cellulitis isolates reveal traits that modulate APEC virulence.

Barnes H.J, Vaillancourt J.P. and Gross W.B. (2003). Newcastle disease, p.631-656. In: Ibid. (Ed.), Diseases of Poultry. 11th ed. Iowa State University Press, Ames.
Barnes H.J., Vaillancourt J.P. and Gross R.G. (1997). Colibacillosis. In: Y. M. Saif, H. J. Barnes, J. R. Glisson, A. M. Fadly, L.R. MacDougal, and D. E. Swayne. Diseases of Poultry, 11thEd. Iowa State University Press, Iowa, USA. 631-652.

Bilge S.S., Clausen C.R., Lau W. and Moseley S.L. (1989) Molecular characterization of a fimbrial adhesin, F1845, mediating diffuse adherence of diarrhea-associated Escherichia coli to HEp-2 cells. J. Bacteriol 171:4281-4289.

Bottero M.T., A. Dalmasso, D. Soglia, S. Rosati, L. Decastelli, and T. Civera. 2004. Development of a multiplex PCR assay for the identification of pathogenic genes of Escherichia coli in milk and milk products. Mol. Cell.Probes. 18(4):283-288.

Calnek B.W., Barnes H.J., Beard C.W., McDougald L.R. and Saif Y.M. (1997). Diseases of Poultry. 10th edition. Iowa State University Press, Ames, Iowa. 131-140.

Carson C.A., Shear B.L., Ellersieck M.R. and Asfaw A. (2001) Identification of Fecal Escherichia coli from Humans and Animals by Ribotyping Appl. Environ. Microbiol. 67(4):1503-1507.

Dho-Moulin M. and Fairbrother J.M. (1999). Avian pathogenic Escherichia coli (APEC). Vet. Res. 30:299-316.

D1'az-Sa'nchez S., Sa'nchez S., Ewers C. and Hofle U. (2012). Occurrence of avian pathogenic Escherichia coli and antimicrobialresistant $E$. coli in red-legged partridges (Alectoris rufa): sanitary concerns of farming. Avian Pathol. 41(4):337-344.

El Tawab A.A., El Aal S.A.A., Mazied E.M. and Morsy D.A. (2015) Prevalence of E. coli in broiler chickens in winter and summer seasons by application of PCR with its antibiogram pattern. Benha Vet. Med.J. 29(2):119-128.

El-Hewairy H.M., Awad W.S. and Ibrahim A.K. (2009) Serotyping and molecular characterization of Escherichia coli isolated from diarrheic and in-contact camel calves. Egypt. J. Comp. Path. and Clinic. Path. 22(1):216-233

Elsayed M.E., Shabana I.I., Esawy A.M. and Rashed A.M. (2015) Detection of Virulence- 
Associated Genes of Avian Pathogenic Escherichia coli (APEC) Isolated from Broilers. J.J. Genetics.1(1): 004. http://genetics.jacobspublishers.com/image s/Genetics/J_J_Gene_1_1_004.pdf

Emery D.A., Nagaraja K.V., Shaw D.P., Newman J.A. and White D.G. (1992) Virulence factors of Escherichia coli associated with colisepticemia in chickens and turkeys. Avian Dis. 36: 504-511.

Hamad M.A., Al-Aalim A.M., Al-Dabbagh S.Y.A. and Ali H.H. (2012) Detection of organ bacterial load in quails. Iraqi $J$ of Vet Scie. 26:47-51

Hasan A.K.M.R., Ali M.H., Siddique M.P., Rahman M.M. and Islam M.A. (2010) Clinical and Laboratory Diagnoses of Common Bacterial Diseases of Broiler and Layer Chickens. Bangl. J. Vet. Med. 8(2):107-115.

Hemmatinezhad B., Khamesipour F., Mohammadi M., Dehkordi F.S. and Mashak Z. (2015) Microbiological Investigation of $\mathrm{O}$ Serogroups, Virulence Factors and Antimicrobial Resistance Properties of Shiga Toxin-Producing Escherichia coli Isolated from Ostrich, Turkey and Quail Meats. J. of food savety. doi: 10.1111/jfs.12199. 1-10

Hussein A.H., Ghanem I.A., Eid A.A., Ali M.A., Sherwood J.S., Li G., Nolan, L.K. and Logue C.M. (2013) Molecular and phenotypic characterization of Escherichia coli isolated from broiler chicken flocks in Egypt. Avian Dis., 57(3):602-611.

Ito H., Skoda S., Kobayashi S., Sugiyama H. and Masanori N. (1990) Colibacillosis of Japanese quail (Coturnix coturnix japonica) occurring in Higashimikawa District. J. Jpn. Vet. Med. Assoc. 43: 661-665.

Jakaria A.T.M., Islam M.A. and Khatun M.M. (2012). Prevalence, characteristics and antibiogram profiles of Escherichia coli isolated from apparently healthy chickens in Mymensingh, Bangladesh. Microbes and Health 1:27-29

Kabir S.M.L. (2010) Avian Colibacillosis and Salmonellosis: A Closer Look at Epidemiology, Pathogenesis, Diagnosis, Control and Public Health Concerns. Int. J.
Environ. Res. Public Health. 7:89-114.

Kalin R., Ongor H. and Cetinkaya B. (2012) Isolation and molecular characterization of Escherichia coli $\mathrm{O} 157$ from broiler and human samples. Foodborne Pathog. Dis. 9(4):313-318.

Knöbl T., Tania A., Gomes, T., Vieira M.A.M., Jose A., Bottinoa J.A., Antonio J. and Ferreira P. (2004) Detection of pap, sfa, afa and fim adhesin-encoding operons in avian pathogenic Escherichia coli. Intern J. Appl. Res. Vet. Med.2(2):135-141.

Law D. (2000) Virulence factors of Escherichia coli O157 and other Shiga toxin-producing E. coli. J. of Appl Microbiol. 88:729-745.

Lee K., French N.P., Hara-Kudo Y., Iyoda S., Kobayashi H., Sugita- Konishi Y., Tsubone H. and Kumagai S. (2011) Multivariate analyses revealed distinctive features differentiating human and cattle isolates of Shiga toxinproducing Escherichia coli O157 in Japan. J. Clin. Microbiol.49: 1495-1500.

Lowy F. (2009) Bacterial Classification, Structure and $\begin{array}{llllllllll} & \mathrm{u} & \mathrm{n} & \mathrm{c} & \mathrm{t} & \mathrm{i} & \mathrm{o} & \mathrm{n} & \text {. }\end{array}$ http://www.columbia.edu/itc/hs/medical/pa thophys/id/2009/introNotes.pdf

Ludwig K., Sarkim V., Bitzan M., Karmali M.A., Bobrowski C. and Ruder H. (2002) Shiga Toxin-Producing Escherichia coli infection and antibodies against stx 2 and stx 1 in household contacts of children with enteropathic hemolytic-uremic syndrome. J. Clin. Microbiol. 40:12-17.

Mamun M.M., Parvej M.S., Ahamed S., Hassan J., Nazir K.H.M.N.H., Nishikawa Y. and Rahman M.T. (2016) Prevalence And Characterization of Shigatoxigenic Escherichia coli in Broiler Birds in Mymensingh. Bangl.J. Vet. Med. 14(1):5-8.

Manoj Kr. Saikia and Saikia D. (2011) PCR Detection of stx 1 and stx2 Toxigenic Genes in Multiple. Antibiotic Resistant Escherichia coli Population and Phenotypic Detection of Esbl Producing Escherichia coli. Isolates from Local Variety of Poultry. Int. J. of Appl. Biol. and Pharmaceut. Technol. 3(2):593602.

Matter L.B., Barbieri N.L., Nordhoff M., Ewers C. and 
Wahyu Prihtiyantoro, et. al.

Horn F. (2011) Avian pathogenic Escherichia coli MT78 invades chicken fibroblasts Vet. Microbiol.148:51-59.

McPeake S.J.W., Smyth J.A. and Ball H.J. (2005) Characterisation of Avian Pathogenic Escherichia coli (APEC) associated with colisepticaemia compared to faecal isolates from healthy birds. Vet. Microbiol. 110: 245-253.

Mitra M., Pramanik A.K., Bhattacharyya H.M., Basak D.K. and Chatterjee A. (2004) Spontaneous colibacillosis in infectious bursal diseaseaffected broiler flocks. Trop. Anim. Health. Prod. 36(7):627-632.

Mohamed M.A., Shehata M.A. and Rafeek E. (2014) Virulence Genes Content and Antimicrobial Resistance in Escherichia coli from Broiler Chickens. Vet. Med. Int. Article ID 195189,6 page https://www.hindawi.com/journals/vmi/20 $14 / 195189$

Monroy M.A., Knobl T., Bottino J.A., Ferreira C.S. and Ferreira A.J.P. (2005) Virulence characteristics of Escherichia coli isolates obtained from broilers breeders with salpingitis. Comp. Immunol. Microbiol. Infect. Dis. 28:1-15.

Moon B.M., Won G.Y., Choi Y.Y., Jin J.K., Oh I.G., Park J.H., Eo S.K. and Lee J.H. (2006) Isolation and characteristics of avian pathogenic Escherichia coli from birds associated with colibacillosis. Proceedings of AZWMP 2006 Chulalongkorn Uni. Fac. of Vet. Sc., Bangkok, Thailand, 26-29 Oct 2006: 61

Nakazato G., Campos T.A., Stehling E.G., Brocchi M. and Da Silveira W.D. (2009) Virulence factors of avian pathogenic Escherichia coli (APEC). Pesq. Vet. Bras. 29:479-486.

Nataro J.P. and Kaper J.B. (1998) Diarrheagenic 17. Escherichia coli. Clin. Microbiol Rev. 11:142-201.

Naylor S.W., Gally D.L. and Low J.C. (2005) Enterohaemorrhagic E. coli in veterinary medicine. Int. J. Med. Microbiol. 295:419441.

Oh J.Y., Kang M.S., Kim J.M., An B.K., Song E.A., Kim J.Y., Shin E.G., Kwon K.J.H. and
Kwon Y.K. (2011) Characterization of Escherichia coli isolates from laying hens with colibacillosis on 2 commercial eggproducing farms in Korea. Poul. Sci. 90:1948-1954.

Radwan I.A., Salam H.H.S., Abd-Alwanis S.A.A. and Al-Sayed M.A.Y. (2014) Frequency of some virulence associated genes among multidrug-resistant Escherichia coli isolated from septicemic broiler chicken. Int J of Adv Res. 2(12):867-874.

Ramirez R.M., Almanza Y., Gonzalez R., Garcia S. and Heredia N. (2009) Avian pathogenic Escherichia coli bind fibronectin and laminin. Vet. Res. Comm. 33:379-386.

Rehman M.U., Rashid M., Sheikh J.A. and Bhat M.A. (2014). Molecular epidemiology and antibiotic resistance pattern of Enteropathogenic Escherichia coli isolated from bovines and their handlers in Jammu, India. J. of Adv. Vet. and Anim. Res. 1:177181.

Rodriguez-Siek K.E., Giddings C.W., Doetkott C., Johnson T.J., and Nolan, L.K. (2005) Characterizing the APEC pathotype. Vet. Res. 36:241-256.

Roy P., Edwin P.G. and Pursushothaman V. (2004) Characterization of Escherichia coli isolates from hatchery and breeder hens. Indian Vet. J. 81:1317-1320.

Roy P., Purushothman V., Kotesswaran A. and Dhillon P. (2006) Isolation, Characterization and Antibimicrobial Drug Resistance Pettern of Eschrichia coli Isolated from Japanese Quail and their Environment. J. Af App Poult Res. 15:442-446.

Roy SR., Rahman M.B., Hassan J. and Nazir K.H.M.N.H. (2012). Isolation and identification of bacterial flora from internal organs of broiler and their antibiogram studies. Microbes and Health 1:72-78.

Saif Y.M., Fadly A.M., Glisson J.R., McDougald L.R., Nolan L.K. and Swayne, D.E. (2008) Diseases of poultry. 12th ed. Blackwell Publishing, London.

Salehi T.Z., Safarchi A., Peighambari S.M., Mahzounieh M. and Khorasgani R.M. 
(2007) Detection of stx1, stx2, eae, espB and hly genes in avian pathogenic Escherichia coli by multiplex polymerase chain reaction. J. Vet. Res. 62(2):37-42.

Salehi Z., Yahya T. and Raeyat R. (2001) Serotyping of isolated Escherichia coli from poultry in Tehran province. J. Fac. Vet. Med. Univ. Tehran. 56:17-20.

Salehi, M. and Ghanbarpour, R. (2010) Phenotypic and genotypic properties of Escherichia coli isolated from colisepticemic cases of Japanese quail. Trop An. Health and Product. 42(7):1497-1504.

Sarah A.Y., Ammar A.M. and Ahmed D.A. (2015) Serological and Molecular Typing of Avian Pathogenic E. coli Originating from Outbreaks of Colibacillosis in Chicken Flocks. Int. J. of Sci. and Res. (IJSR) 4(2): 2062-2088.

Sepehri G. and Zadeh A.H. (2006) Prevalence of bacterial resistance to commonly used antimicrobials among Escherichia coli isolated from chickens in Kerman Province of Iran. J. Med. Sci. Pakistan. 6(1):99-102.

Soon-Gu K., Se-Yeoun C., Eun-Ju C., Kim B., HeeJong S. and Hyung-Kwan J. (2008) Epidemiological Prevalence of Avian
Pathogenic Escherichia coli Differentiated by Multiplex PCR from Commercial Chickens and Hatchery in Korea. $J$ of Bacteriol and Virol.38(4):179-188.

Suryani A.E., Karimy M.F., Istiqomah L., Sofyan A., Herdian H. and Wibowo M.H. (2014) Colibacillosis Prevalence In Broiler Chicken Infected By Escherichia coli With Administration of Bioadditive. Probiotic andAntibiotic Widyariset, 17(2):233-244.

Talebiyan R., Kheradmand M., Khamesipour F. and Rabiee-Faradonbeh M. (2014) Multiple Antimicrobial Resistance of Escherichia coli Isolated from Chickens in Iran. $\mathrm{H}$ i n d a w i $\mathrm{P}$ u blis h i g Corporation.Veterinary Medicine International Article ID 491418, 4 pages http://dx.doi.org/10.1155/2014/491418

Zinnah M.A., Bari M.R., Islam M.T., Hossain M.T., Rahman M.T., Haque M.H., Babu S.A.M., Ruma R.P. and Islam M.A. (2007) Characterization of Escherichia coli Isolated from Samples of Different Biological and Environmental Sources. Bangl. J. Vet. Med. 5 (1 and 2):25-32. 